\author{
Анна Стасенко \\ Жешовский университет (Польща)

\section{ПЕРЦЕЛЛЯЦИЯ ОБСТОЯТЕЛЬСТВ В СОВРЕМЕННОМ РУССКОМ ЯЗЫКЕ (НА МАТЕРИАЛЕ ХУДОЖЕСТВЕННЫХ ТЕКСТОВ)}

Парцелляция - это особый способ членения единой синтаксической структуры, т. е. предложения на две или несколько коммуникативно самостоятельных фраз (Розенталь, Теленкова 2001: 310; Ярцева 1990: 369), напр.: Он (...) тоже пошел. В магазин. Сигарет купить (Шукшин). В речи парцелляция осуществляется посредством интонации, а в письменном тексте ее графическими показателями являются знаки препинания - знаки конца предложения, т. е. точка, многоточие, вопросительный и восклицательный знаки. (Копнина 2008: 102; Сковородников 1980: 86). Парцелляция как особая форма представления предложения в тексте потенциально возможна во всех языках, что позволяет считать ее универсалией речи (Ярцева 1990: 369).

Парцеллированное предложение состоит из базовой (основной) части и парцеллята (парцеллирующей части). Базовая часть - это фраза, которая является структурной основой, организующей высказывание в структурное и смысловое целое вместе с парцеллятом. Фраза, в которой реализуется структурно зависимая часть предложения, называется парцеллятом (Бабайцева 2000: 553; Ванников 1979: 58-59; Копнина 2008: 102). Парцелляты могут находиться как в контактной, так и в дистантной позиции относительно базовой части предложения (Копнина 2008: 102; Ярцева 1990: 369).

Разделение высказывания на части часто оценивается как стилистическое средство выделения наиболее актуальной с точки зрения автора информации, а также как один из приемов экспрессивного синтаксиса (Сидорова 2010: 150; Сибгатова 2010: 188-191). Парцеллированное высказывание можно восстановить, но тогда утрачивается его экспрессивный характер. Ср. примеры: В дверь позвонили. Упорно и настойчиво. и В дверь позвонили упорно и настойчиво (Суров). Первая конструкция - парцеллированная является более экспрессивной (Бабайцева 2000: 554).

Многие отмечают, что парцелляция - это «явление живое, активное, преуспевающее», которое используется главным образом в языке современ- 
ной художественной литературы и в публицистике. В научных и научно-популярных текстах парцелляция не выступает. Основной функцией этого синтаксического приема является функция смыслового усиления и экспрессивного выделения определенной части высказывания (Розенталь, Теленкова 2001: 310; Сковородников 1980: 86). С точки зрения актуального членения предложения, парцелляция служит средством выделения в предложении (высказывании) наиболее важного момента, т. е. создания нового самостоятельного рематического центра или нескольких таких центров (Копнина 2008: 102; Сковородников 1980: 86).

В лингвистической литературе явление парцелляции не имеет полного и однозначного определения, что связано с многоплановостью самой парцелляции, а также с различием подходов к ее исследованию (Ваулина 2008: 458-464). В. В. Бабайцева обращает внимание на синкретизм парцелляции и присоединения (Бабайцева 1997: 56-65; Бабайцева 2000: 553-560). Эти термины понимаются лингвистами неоднозначно. Так, например, А. П. Сковородников определяет присоединение как грамматическую категорию и явление статического аспекта предложения, а парцелляцию как стилистический прием и явление динамического аспекта предложения (Бабайцева 2000: 554; Сковородников 1978: 121). По мнению Л. Ю. Максимова, парцелляция - это прием, принадлежащий книжной речи, а присоединение - это явление живой устной речи (Бабайцева 2000: 554). Парцелляцию и присоединение невозможно строго разграничить, так как во многих случаях допускается двоякое толкование. В Словаре-справочнике лингвистических терминов разница между парцелляцией и присоединением определяется следующим образом: «От присоединения парцелляция отличается тем, что парцеллируемые части всегда находятся вне основного предложения, тогда как присоединительные конструкции могут быть как в рамках основного предложения, так и за его пределами (в последнем случае парцелляция и присоединение фактически совпадают» (Розенталь, Теленкова 2001: 310). Наиболее общим различием между этими явлениями считается факт, что при парцелляции происходит отчленение фрагмента от основной (базовой) части, а при присоединении - добавление, присоединение к базовой части (Бабайцева 2000: 555).

Предметом исследования в настоящей статье являются предложения с парцелляцией обстоятельств, отобранные из текстов современной русской художественной литературы ${ }^{1}$.

1 Фактографический материал был отобран из следующих произведений в электронной версии: В. Аксенов, Остров Крым; В. Аксенов, Скажи изюм; Д. Балашов, Марфа-посаднииа; В. Барабашов, А смерть подождет; Б. Васильев, А зори здесь тихие..; А. Грановский, Властелин видений (Гиблое место - 6); Я. Ильясов, Согдиана; Н. Медведева, А у них была страсть и Б. Акунин (2004), Туреиякий гамбит, Москва. 
Обстоятельство - это второстепенный член предложения, характеризующийся разнородностью и разнообразностью и не являющийся структурно строго необходимой частью предложения. Оно выступает в предложении только в случае, когда автор хочет актуализировать, подчеркнуть тот или иной аспект ситуации. Потому среди второстепенных членов предложения наиболее частотны парцелляты, содержащие обстоятельство (Сидорова 2010: 152). Анализ отобранного материала показал, что парцеллироваться могут обстоятельства разных типов:

1. Обстоятельства образа действия, характеризующие способ протекания действия, названного сказуемым в базовой части предложения. Парцелляты-обстоятельства образа действия могут выражаться наречиями, напр.:

Перенес все сумки. Спокойно. (Медведева)

Это он нарочно кричал, чтоб бодрость появилась. У бойцов от команды бодрость появляется, это он по себе знал. Точно. (Васильев)

- Хватит, Пастырь! - Тотчас же золотистая пелена спала с глаз Первохода. - Отойдите от парня на три шага! Живо! (Грановский)

- Команду - в ружье: боевая тревога! Кирьянову ко мне. Бегом! (Васильев)

В последнем примере, мотивированное существительным наречие, бегом обозначает способ передвижения.

В отдельную, самостоятельную фразу может выделяться больше чем одно обстоятельство образа действия:

- Иди спать, - сказал он. - Я устал, мне рано ехать.

И зевнул. Длинно, равнодушно, с завыванием. (Васильев)

Парцеллят состоит из трех однородных обстоятельств, выраженных наречиями и именем существительным.

Значение парцеллированного наречия в обстоятельственной функции может уточняться:

Он уяснил себе степень опасности. Вполне отчетливо. (Аксенов)

Обстоятельство образа действия отчетливо сопровождается наречием вполне, подчеркивающим его полную меру.

В парцелляте возможно также повторение обстоятельства, имеющегося в базовой части, напр.:

Да, дум набралось кубометра на два, не меньше. И с каждой думой совершенно особо разобраться надо. Совершенно особо... (Васильев) 
Плакала на пеньке, пока ее не отыскала Рита Осянина.

- Ну чего ты, дурешка? Проще жить надо. Проще, понимаешь? (Васильев)

Тронулись, слава тебе... Он впереди шел, Четвертак с Комельковой - основным ядром, а Осянина замыкала. Сторожко шли, без шума, да опять, видно, к себе больше прислушивались, потому что чудом на немцев не нарвались. Чудом, как в сказке. (Васильев)

В первом примере повторяется целое словосочетание: обстоятельство образа действия особо и, подчеркивающее его полную меру наречие совершенно. Во втором случае к парцелляту - обстоятельству образа действия добавлен глагол понимаешь. Как повтор, так и глагол, подчеркивают важность парцеллированной фразы, обращая на нее внимание читающего. В последнем тексте наречие чудом повторяется в парцелляте и сопровождается сравнительным оборотом, который уточняет способ совершения действия.

В нашем материале имеются также примеры парцеллированных обстоятельств образа действия, которые выражаются именем существительным с предлогом или словосочетанием наречного характера:

- Но как же без узды церковной все же? Без икон, без обрядов, постов, без исповеди и покаяния?

- Пост блюди! Земле и Богу исповедуйся! В духе, а не в букве, в духе! (Балашов)

Одно оставалось: к болотам отходить. Ног не жалея. (Васильев)

В обоих примерах парцелляты обладают переносным значением.

2. Обстоятельства места, указывающие на место, путь движения или направление действия, названного сказуемым в базовой части предложения. Парцелляты-обстоятельства в большинстве случаев обозначают собственно место, напр.:

Она писала: «Ты должен сейчас уехать. Нам негде быть вместе. Лучше я приеду. $B$ Ленинград». (Медведева)

Они пили вино из одного стаканчика из-под горчицы. И Женщина думала, что совсем так же они могли бы лежать в Ленинграде, пить из настоящих бокалов, и в окна по два с половиной метра высотой стучал бы дождь. Где-нибудь на Васильевском острове. (Медведева)

- Ты дура просто! Ты живешь легенду, свою, нашу! Ты себя со стороны не видишь. На моем фоне, может, у тебя ничего и нет. Но у тебя уже две книги. Во Франщии. И в Германии. (Медведева)

В последнем примере имеются два парцеллята-обстоятельства. Союз $u$, который начинает второй парцеллят, указывает на его добавочный характер и факт, что в нем выражается мысль, которая вдруг пришла в голову. 
Среди рассматриваемых предложений имеются также случаи, в которых в первом парцелляте обстоятельство называет направление, а во втором место:

- Бежать? - Спантамано вскинул брови. - Куда?

- На север. В Согдиану. Ороба, правитель Наутаки, мой друг. Он примет меня. (Ильясов)

Место действия может указываться в базовом предложении в общих чертах, а потом конкретизироваться в парцелляте:

Она отправила его туда, где он жил, где были его вещи. $3 a$ город. Потому что он весь пылал, горел. (Медведева)

Также в следующих примерах парцеллируемые обстоятельства уточняют места, названные обстоятельством в главном предложении, что добавочно подчеркивается употреблением глагола значит и посредством отрицания:

- Мыслю я, тол они несли. А если тол, то маршрут у них совсем не на шоссе, а на железку. На Кировскую дорогу, значит. (Васильев)

- Тогда, под Аргуном, и дядя мой погиб, вместе с вашими. Ваха. Мы его дома похоронили, в селе. Не в Гудермесе. (Барабашов)

Интересный также пример, в котором в главной части обстоятельство выражается наречием так, имеющим общее значение таким образом:

Женщина думала, что Писатель так жить не хочет. На вулкане. То есть под ним. (Медведева)

В первом парцелляте объясняется, что так обозначает место жизни, а во втором это место еще уточняется.

Парцеллированные обстоятельства называют также путь движения, напр.:

- Стало так! - говорила Марфа. - Скачите сейчас на Липну, там мои ратники ждут. Omсюда через Ковалево. (Балашов)

3. Обстоятельства времени, указывающие на время действия или состояния названного в базовом предложении. Парцеллированные обстоятельства этого типа могут выражаться наречиями, напр.:

...Ваха появился дома на четвертые сутки засады. Ночью. (Барабашов)

Знаешь, что я думаю? Что тебе лучше остаться здесь. Навсегда. (Грановский)

Она принесла из кухни пиво и стаканы. Пиво купил Критик. Рано утром. (Медведева)

Все в ней вдруг запеклось и потому не болело и не кровоточило. Словно ждало разрешения, но разрешения этого Женька не давала, а потому ничто теперь не отвлекало ее. Такое уже было однажды, когда эстонка ее прятала. Летом сорок первого, почти год назад... (Васильев) 
В вышеуказанных текстах парцеллированные обстоятельства времени выражаются наречиями. Первое называет часть суток, а второе длительность действия (навсегда, т. е. на все время, на всю жизнь). В двух последних примерах наречия выступают с другими словами, дающими более точное определение времени действия, названного в базовом предложении: утром сочетается с наречием рано, называющим начальную пору, а летом сопровождается названием года и словосочетанием почти год назад, относящим время состояния к моменту речи.

Время действия указывается также посредством парцеллированных обстоятельств, выраженных существительным с предлогом:

Они были знакомы уже черт знает сколько лет. И когда у художника не было этого шикарного ателье - а жил он в малюсенькой комнатенке на острове, - он приходил со своей еще еле шагающей дочкой к Писателю с Женщиной по субботам. После синагоги. (Медведева)

- Дети?.. - вздохнул Федот Евграфыч. - Был мальчонка. Помер. Аккурат перед войной. (Васильев)

А семья... Только отец, которого я горячо люблю и по которому очень скучаю. Он сейчас во Франции. Когда-нибудь расскажу вам о нем. После войны, ладно? Это целая история. (Акунин)

Существительные, употребленные в парцеллятах-обстоятельствах не являются названиями отрезков времени. Они определяют время через отнесение к времени событий (перед/после войны - перед тем, как началась война/после того, как закончилась война, после синагоги - после времени проведенного в синагоге). Во последнем высказывании парцеллированное обстоятельство времени конкретизирует обстоятельство в главной части, выраженное наречием когда с частицей -нибудь, которая вносит значение неопределенности.

Парцеллироваться может больше чем одно обстоятельство времени, напр.:

- Когда это он начнёт? Да когда эта новая собака станет второй Линдой, Проскурина?

Через год? Или два? А остановки взрывают сегодня, сейчас! (Барабашов)

- Ч-то с тобой? - пробормотал он растерянно.

- Что со мной? Разве ты не видишь, старый верблюд, что со мной? Я хочу жениться на твоей дочери. Сегодня же. Сейчас же! (Ильясов)

В первом примере имеются два парцеллята-вопроса. Второй начинается союзом или, присоединяющим обстоятельство дополняющее высказанную мысль. В последнем тексте в парцеллятах указывается точное время дей- 
ствия, а градация обращает внимание на его немедленность. Употребление восклицательного знака добавочно подчеркивает экспрессивность выделенной фразы.

4. Обстоятельства меры и степени, характеризующие меру и степень проявления действия, состояния или признака, названного сказуемым базовой части предложения, напр.:

- А остальные?

- Кузьменков погиб. Который перед тобой сидел, за спиной!

- А-а... Трое, значит. Ну, я четвертый буду. Сил никаких, Лёша! Плывет всё перед глазами...

- Не спеши, старик, смерть подождет, сам же как-то говорил. Раненый, да. Тяжело. Но ничего, выберемся... (Барабашов)

«Она не любит меня, - печально думал Олег. - Или очень испугалась, увидев меня таким. И я ей теперь не нужен. Совсем. Инвалид, калека...» (Барабашов)

- Держи, Рита, еще рожок к автомату. Только издаля не стреляй. Через речку из винтовки бей, а автомат прибереги. Как форсировать начнут, он очень даже пригодится. Очень. Поняла ли? (Васильев)

Bсе парцеллированные наречия указывают на высокую степень проявления признака. Отчленение названных обстоятельств от базовой части предложения и факт, что в последнем примере парцеллированное обстоятельство это повторение обстоятельства, имеющегося в главной части, добавочно подчеркивают эту степень.

Высокая степень выражается тоже в парцеллятах в нижеприведенных текстах:

Хватит тех, что погибли. По горло хватит, до конца жизни. (Васильев)

- Пример покажи, - улыбнулась Кирьянова. И Рита сразу замолчала. Она даже представить не могла, что такое может случиться: мужчин для нее не существовало. Один был мужчина - тот, что вел в штыковую поредевшую заставу на втором рассвете войны. Жила, затянутая ремнем. На самую последнюю дырочку затянутая. (Васильев)

В последнем парцелляте выражение на самую последнюю дырочку называет высочайшую степень совершения действия. В конце фразы имеется еще повтор сказуемого главного предложения.

Интересный также пример с парцелляцией двух обстоятельств меры:

- С год назад Хлопуша сказал, что хочет пойти в Гиблое место. Еще сказал, что коли я его туда не отведу, он пойдет сам. И я его отвел. Недалеко. Версты на четыре от межи. (Грановский) 
Первый парцеллят - наречие недалеко дает общую меру пространства, указывая на незначительное расстояние. Во втором парцелляте имеется точное определение этого расстояния.

5. Акцессуарные обстоятельства, сопутствующие реализации содержания главной предикативной связи, напр.:

Он еще не рукоположен, не поставлен... После! Пусть ответят из Москвы, пусть митрополит утвердит его на архиепископии. После можно будет и рассмотреть. Не торопясь. За февралем, в грядущем году... (Балашов)

- Ты здесь? В темноте... Лежишь. Я тебя запер... - Он говорил шепотом, потому что в темноте можно только шепотом. (Медведева)

Сочетания не торопясь и в темноте указывают на обстановку, в которой совершается действие.

6. Обстоятельства причины, обозначающие причину действия, состояния или признака:

У него было горячим все - язык был очень горячим. Теперь уже по-другому горячим. Из-за температуры.. (Медведева)

Итак, выходило, что все-таки неравнодушен, но соперничать с Соболевым не желает. Верно, из гордости. (Акунин)

В приведенных примерах, обстоятельства из-за температуры и из гордости называют причину состояния и действия, названного сказуемым в базовом предложении. Во втором примере наречие верно выражает подтверждение.

7. Обстоятельство цели обозначает цель действия, названного сказуемым в базовой части предложения. Парцеллят-обстоятельство цели выражается словосочетанием:

- А ты куда, отец, рулишь?

- В Брюссель. Освещать сессию Совета НАТО. Октябрь, кажется, тоже там будет. (Аксенов)

В данной реплике диалога имеется эллипсис сказуемого и парцелляция словосочетания, выполняющего функцию обстоятельства цели. 
Проведенный анализ предложений с парцелляцией обстоятельств, отобранных из современной русской художественной литературы показывает, что от базовой части точкой отделяются наречия, существительные и словосочетания, характеризующие способ протекания, место, время, меру и степень, обстановку, причину и цель действия, состояния или признака, названного сказуемым в базовой части предложения.

В отдельную, самостоятельную фразу могут выделяться одно или два однородных обстоятельства в случае, когда в главном предложении они отсутствуют. Однако, имеются также высказывания с парцеллированными обстоятельствами-повторами обстоятельств, имеющихся в базовом предложении или такими, которые конкретизируют значение обстоятельства в базовой части. Парцелляция обстоятельства и расчленение предложения на несколько интонационно-смысловых речевых единиц позволяет увеличить информацию и одновременно упрощает и облегчает базовое предложение.

Отделение точкой обстоятельств иногда сопровождается другими средствами: повторами, градацией или употреблением слов усиливающих значение обстоятельства. Парцелляция в сочетании с названными приемами придает высказыванию динамичность, выделяет самые важные элементы в предложении и притягивает к ним внимание.

Результаты проведенного анализа послужат в дальнейших исследованиях над явлением парцелляции в структуре простого и сложного предложений в сопоставительном плане в современном русском и польском языках.

\section{Библиография}

Бабайцева В. В. (1997), Синкретизм парцеллированных и присоединенных субстантивных фрагментов текста, «Филологические науки», №4, с. 56-65.

Бабайцева В. В. (2000), Явления переходности в грамматике русского языка, Москва, с. 553. Большой энииклопедический словарь. Языкознание (1990), ред. В. Н. Ярцева, Москва, с. 369.

Ванников Ю. В. (1979), Синтаксис речи и синтаксические особенности русской речи, Москва, с. $58-59$.

Ваулина Т. Л. (2008), К вопросу о разграничении присоединения и париелляиии, «Проблемы истории, филологии, культуры», №22, Магнитогорск, с. 458-464.

Копнина Г. А. (2008) Париелляция, http://library.krasu.ru/ft/ft/_articles/0070223.pdf, c.102.

Розенталь Д. Э., Теленкова М. А. (2001), Словарь-справочник лингвистических терминов, Москва, с. $310,614$.

Сибгатова Э. И. (2010), Париеллированные конструкиии как средство выражения экспрессии в романе В. Аксенова Остров Крым, «Вестник ТГГПУ», №4 (22), с. 188-191.

Сидорова Е. Г. (2010), Париеллированные конструкичи в структуре современного газетного текста, «Acta Universitatis Lodziensis, Folia Linguistica Rossica», №6, c. 149-155.

Сковородников А. П. (1978), О соотношении понятий „парцеллящия” и „присоединение”, «Вопросы языкознания», №1, с. 118-129.

Сковородников А. П. (1980), О функциях париелляции в современном русском литературном языке, «Русский язык в школе», №5, с. 86-91. 


\title{
Anna Stasienko
}

\section{ON THE PARCELED ADVERBIALS IN THE RUSSIAN LANGUAGE (BASED ON MODERN RUSSIAN LITERATURE)}

\author{
(Summary)
}

The article deals with the phenomenon of parceling, i.e. the division of a sentence into small parts, in modern Russian. Parceled sentence consists of a main (basic) part and a partcellator.

Different types of parceled adverbials and the role of parceling in such sentences have been discussed.

Keywords: parceling, parceled adverbial, main part of a sentence, partcellator.

\author{
Анна Стасенко
}

ПЕРЦЕЛЛЯЦИЯ ОБСТОЯТЕЛЬСТВ

В СОВРЕМЕННОМ РУССКОМ ЯЗЫКЕ

(НА МАТЕРИАЛЕ ХУДОЖЕСТВЕННЫХ ТЕКСТОВ)

(Резюме)

В статье рассматривается явление парцелляции, т.е. особого способа членения предложения на две или несколько коммуникативно самостоятельных фраз в современном русском языке. Парцеллированное предложение состоит из базовой (главной) части и парцеллята.

Предметом описания являются парцелляты-обстоятельства разных типов и некоторые функции парцелляции.

Ключевые слова: париеллячия, париеллированное обстоятельство, базовая часть предложения, париеллят. 